\title{
DESENVOLVIMENTO DE UM PORTAL WEB PARA IGREJAS
}

\section{Céfas Soares de Souza ${ }^{1}$ \\ Marcos Fernando Rosa ${ }^{2}$ \\ Ney Cândido da Silva Ribeiro}

Resumo: Este artigo aborda a problemática enfrentada por pequenas e médias igrejas católicas que querem fazer uso de web sites para levar informações e serviços a seus fiéis e, apresenta uma solução que está ao alcance de todas. Muitas igrejas gostariam de possuir um site para permitir um maior contato com o fiel, possibilitando assim maior interação entre a comunidade e a igreja. Entretanto, muitas igrejas não possuem recursos financeiros para manter um profissional gerenciando esse serviço ou algum membro da igreja capacitado para isso. Diante deste cenário este trabalho propõe o desenvolvimento de um portal web que possibilitará a qualquer pessoa gerenciar, de forma dinâmica, o conteúdo disponível no site de uma igreja, como se fosse o conteúdo de um perfil em uma rede social. Isso torna desnecessário o investimento com pessoas especializadas e mantêm um investimento de baixo custo para manter o serviço.

Palavras-chave: Php; Web site; Igrejas; Fácil utilização.

\footnotetext{
1 Sistemas de Informação/FEPI, Brasil. E-mail: cefas.soares@yahoo.com.br.

2 Sistemas de Informação/FEPI, Brasil. E-mail: marcosand89@gmail.com.

${ }^{3}$ Sistemas de Informação/FEPI, Brasil. E-mail: ney.candido.ribeiro@gmail.com.
} 